This item was submitted to Loughborough's Research Repository by the author.

Items in Figshare are protected by copyright, with all rights reserved, unless otherwise indicated.

\title{
Exploring SME perceptions of sustainable product service systems
}

PLEASE CITE THE PUBLISHED VERSION

http://dx.doi.org/10.1109/TEM.2012.2215961

PUBLISHER

(c) IEEE

VERSION

AM (Accepted Manuscript)

LICENCE

CC BY-NC-ND 4.0

REPOSITORY RECORD

Hernandez-Pardo, Ricardo J., T.A. Bhamra, and Ran S. Bhamra. 2019. "Exploring SME Perceptions of Sustainable Product Service Systems". figshare. https://hdl.handle.net/2134/13109. 
This item was submitted to Loughborough's Institutional Repository (https://dspace.lboro.ac.uk/) by the author and is made available under the following Creative Commons Licence conditions.

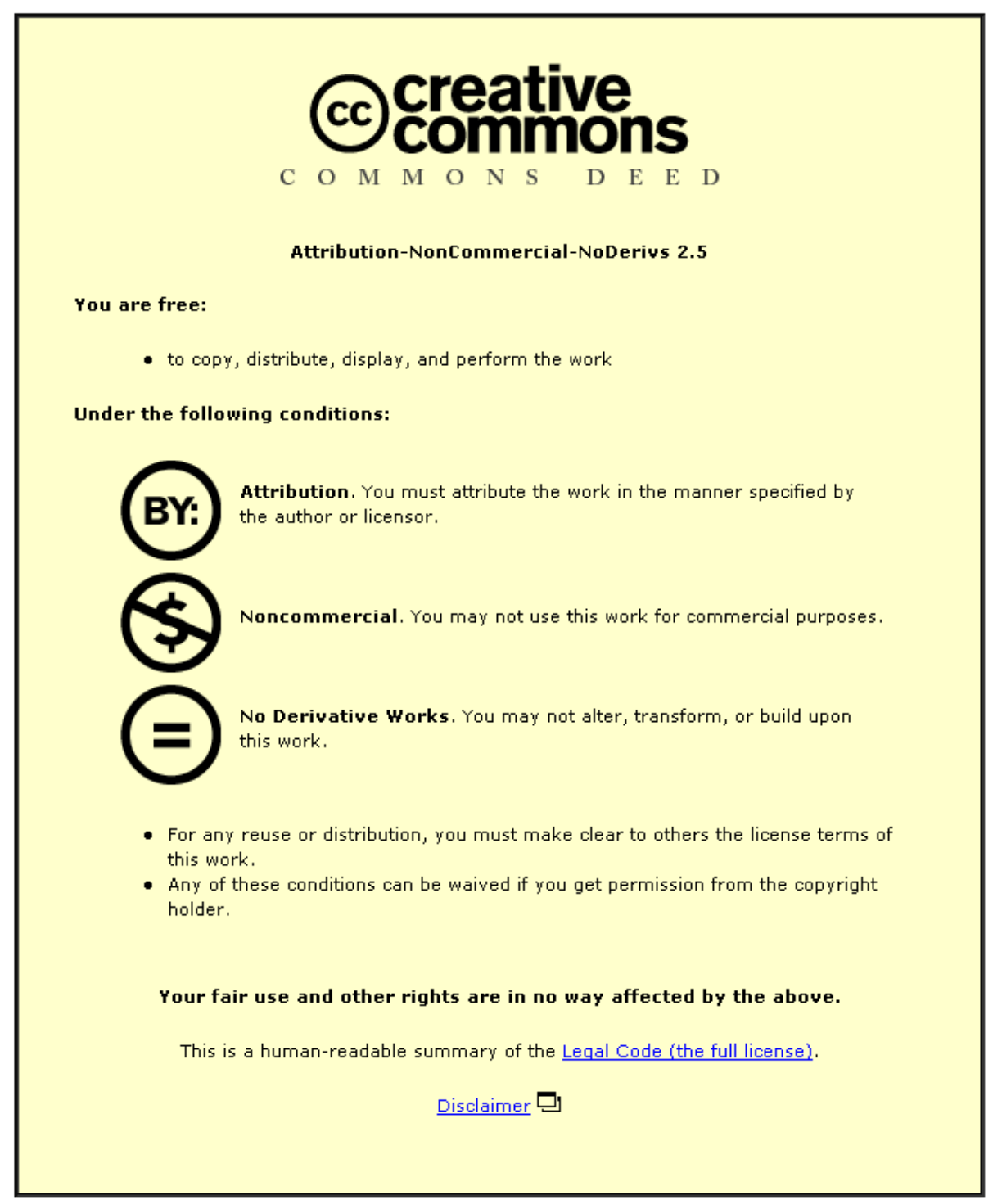

For the full text of this licence, please go to: http://creativecommons.org/licenses/by-nc-nd/2.5/ 


\title{
Exploring SME perceptions of Sustainable Product Service
}

\section{Systems}

\author{
Ricardo J. Hernandez-Pardo, Tracy Bhamra and Ran Bhamra, Loughborough \\ University, Loughborough, UK.
}

Keywords: Innovation, Design Process, Product Service Systems, ICT, SME, Cooperation, Business Development

\begin{abstract}
This paper explores the perception of a group of Colombian Small and Medium Enterprises (SMEs) towards sustainable Product Service Systems (PSS) development. There is currently much interest in the area of PSS however, studies of sustainable PSS involving SMEs are lacking. The purpose of this research was to identify those organizational aspects that can contribute to develop sustainable PSS in SMEs. Four main areas were explored: sustainable awareness, use of Information and Communication Technologies (ICTs), design process and business strategy. This study was carried out in cooperation with the Colombian Ministry of ICT and highlights their desire to find new routes to encourage transformation of companies towards competitive and sustainable industrial sectors. A significant finding is that the integration between Design Process and ICTs appears to be a key mechanism in developing sustainable PSS in SMEs. Finally, further work in this field of research is discussed and highlighted.
\end{abstract}

\section{Managerial Relevance Statement}

This paper aims to help managers to explore new production systems better aligned with sust 
ainable principles. One potential concept in this area is Product Service Systems (PSS), whic $\mathrm{h}$ has shown great potential to be a sustainable business model but has not achieved the mome ntum needed in its development, particularly in small and medium enterprises (SMEs). This p aper explores SMEs perceptions of sustainable PSS. First insights about aspects to consider in an organizational transformation towards sustainable PSS are established.

\section{INTRODUCTION}

The development of sustainable businesses requires firms to consider environmental and social welfare in the same way that they consider economic prosperity. This way of working requires different products and services to traditional ones and different ways to produce them [1], [2]. In this sense rapid and radical organizational change is required to develop these sustainable models [1], [3]. Despite the advances in fields such as cleaner production, ecodesign and environmental management there are other concepts that can contribute to this development of sustainable businesses. Product Service Systems (PSS) is one of these concepts that can produce the radical change needed [4]. However not all types of PSS have the potential to bring sustainable results into a business. In this paper a particular type of sustainable PSS are considered, defined not only in terms of the value created by the integration of products and services, but also by its potential to be a sustainable system. This

is a system that contributes to improve the environmental and social performance of the business conserving and enhancing its economic profitability [5].

The paper recognizes another trends related mainly to industrial PSS where the potential to be a sustainable system is not necessarily part of the incentive to develop a PSS, however these are not the type of PSS considered here. These industrial PSS are mainly business-to-business systems that operate on a medium to large scale, whilst sustainable PSS considered here are generally businesses to customer systems that operate on small and medium scale. In this paper the terms PSS and sustainable PSS are used to refer in general to these particular PSS 
with the motivation and potential of been sustainable systems. In these sense PSS are considered as integrated solutions where products and services are mixed together to satisfy the customer need, often in very innovative ways that demand deep transformation in the organization including the ownership of the offer and with a clear potential to be sustainable systems [6]. However there are few examples of these systems to study in practice and even less related to small and medium enterprises (SMEs). According to Creusen [7] one of the difficulties in developing PSS is achieving products and services consistent with each other and consistent with the aim of the PSS, Ways to ensure that product values and meanings are aligned within a PSS is an issue for further research: how can the product support the value of the service, and how can the abstract values of the service be expressed in the design of the product?"' In this sense Tukker [4] Mont [8] and Ness [9] have mentioned how the development of PSS is related to the design and redesign of products and services with different purposes to traditional ones, purposes such as use and reuse, recycling, remanufacture, leasing and sharing. These purposes are in general the basis of a PSS and products and services have to be designed to fulfil that purpose, but more research in this area is needed as is outlined by Creusen [7] above.

Previous work has suggested that Information and Communication Technologies (ICTs) can contribute to developing PSS [3], [4], [6], [8], [10]. PSS in conjunction with ICTs present great opportunities for virtualization and dematerialization of offers [11]. However, ICTs can contribute to developing sustainable PSS in more ways than purely virtualization, [11-15]. The literature has identified important areas of opportunity related to designing smart green products, encouraging green purchasing and facilitating the exchange of information about environmental and social behaviour of firms based on the use of ICTs that can contribute to develop PSS [13], [14], [16]. Some of these opportunities are related to changing the attributes of the product and this implies changes in the design process. In this sense ICTs 
should be seen not only for their contribution as a means to deliver services in a PSS but also as a mechanism to transform the design process to enable the PSS [17]. However little is known about the possible changes that the use of ICTs can produce in the design process and in the resulting products in terms of the possible contribution to develop sustainable PSS.

Addressing these issues an exploratory study with a group of thirty-eight Colombian SMEs is presented. The objectives of this research were to:

- Identify the perception of these SMEs about the concept of PSS and their disposition to develop this kind of systems in their organizations.

- $\quad$ Determine if sustainability is a priority for these SMEs and identify previous approaches to the topic.

- Explore what the main motivations are in these SMEs to use ICTs, what technologies they are using and the impact of these motivations and technologies on the development of PSS.

- Make an initial exploration of the relationships between PSS, sustainability, ICTs and the design process in these SMEs.

Achieving these objectives provides a first diagnostic of the situation that could help to support SMEs to develop sustainable PSS. In the following section the theoretical background is presented followed by the methodology used to select the firms and collect the data, the findings from the survey of Colombian SMEs and finally a discussion is provided to help orient future research in this field. The scope of the research covers only the exploration of the topics. However in the final discussion in section 5 potential relationships between these topics that can contribute to develop sustainable PSS in SMEs are introduced as a reference model.

\section{CONCEPTUAL BACKGROUND}

\subsection{Sustainability in SMEs}


The adoption of the concept of sustainability by industry is becoming increasingly essential. Isolated actions especially around environmental concerns have been evolving to strategic and complex programs involving companies, governments and the public [18]. Initiatives, theoretical models and exploratory studies have been used to determine the main drivers and barriers of this inclusion mainly focusing on large enterprises [19], [20]. These preliminary studies have shown the difficulties of developing sustainable businesses and some of the requirements such as the change of technologies, the strategic compromise of top management, large investment and competences such as flexibility, creativity, and strategic thinking required to innovate and communicate effectively with consumers and other stakeholders. According to Hofman and De Bruijn [2] sustainable development requires radical innovation transforming organizations, products and processes. This radical innovation illustrates that not only individual efforts but also collaborative schemes with shared visions of sustainable systems are needed [2]. In terms of organisations, this radical innovation means not only transforming how they work but especially how they perceive themselves. This transformation is challenging for large companies, but in the case of SMEs it could be even more difficult to achieve because of some common barriers such as lack of knowledge and training, lack of awareness and limited financial resources [21].

Ciliberti et al. [22] report particular threats for SMEs in developing economies as the lack of mentorship and skills transfer, communication gaps, lack of support networks, poor infrastructure, low savings rate and difficulty in accessing financial capital. This set of barriers to change are enlarged in terms of the development of sustainable businesses by the lack of awareness of issues such as environmental legislation and social impacts derived from industry, and the perception that SMEs have small impacts compared with larger enterprises [21], [22]. Moreover, according to Sarkis et al. [23] it is unlikely that a single organization can carry out this transformation on an individual basis. Sustainable systems require the 
interrelation of multiple actors such as governments, academia, consultancies and research centres, suppliers, distributors, sellers and producers [18], [23]. In this sense part of the challenge is supporting the inclusion of SMEs into these systems. There are many reasons why this support has to be given. SMEs are important in the world economy and their combined impacts are very significant [21]. SMEs represent at least $80 \%$ of all global enterprises [24] and in UK they are almost 99\% of the total number of enterprises [25]. In Colombia these figures are even larger with $99.86 \%$ of companies being SMEs and of them 96.4\% are Micro-enterprises with less than 10 employees [26]. SMEs are also considered as very flexible firms because of their size and lack of rigid structures, characteristics that make it possible to respond quickly to market pressures and to adapt to new business conditions. These last features are key points to enable radical innovations and develop models such as PSS, but they are not sufficient, SMEs require support from external actors and simple mechanisms to produce these changes [23], [26]. Sarkis et al. [23] outline the actors that can be part of these systems as academia, policy makers, non-governmental organizations and public. In the case of PSS it is not yet clear how these actors can work together, how the support should be given, and what mechanisms should be used to develop the concept in SMEs. However PSS as a concept has shown great potential to develop sustainable business. Finally, the development of sustainable business in SMEs in developing economies has to be framed by the dichotomy between growing to reach better standards of living, that imply increasing consumption of resources and productions of goods against achieving that growth with innovative ways demanding fewer resources [27]. PSS could satisfy that necessity of innovative and less resource intensive business solutions.

\subsection{Product Service Systems}

PSS are considered as integrated solutions where products and services are mixed together to satisfy the customer needs, often in very innovative ways that demand deep transformation in 
the organization including the ownership of the offer and with a clear potential to be sustainable systems [6]. In this way PSS can contribute to achieving sustainable business supported by moving the focus from producing and selling physical products to designing and selling systems of services and products that together can satisfy the user needs with less or more efficient use of resources and usually longer life cycles [6]. These integrated solutions could present benefits for the three dimensions of the bottom line [8] which are environment, society and economy. When considering society they can create awareness about the relationship between the stakeholders, build collaborative networks, make markets more diverse benefiting consumers and can be more human capital intensive presenting opportunities to increase employment. Also PSS can enable poor people to access services through communal and rental systems [9]. In environmental terms they contribute to decoupling economies, dematerialisation, decreasing consumption rates by alternative scenarios of product use, and finally more efficient use of materials and renewable resources. In economic terms new markets opportunities, higher market value, competitiveness, stronger innovation orientation, higher operating efficiencies and cost savings are some of the benefits mentioned [28].

Despite these benefits PSS are still at an early stage of research [9] and there are few successful examples of these kinds of systems with a sustainable focus developed by small firms. Van Halen et al. [29] mention cases such as Xerox Document Services (Documents Processing), NorLux - LED Light Services (Lighting), Call a bike (Urban Mobility), Liftshare (Urban Mobility), Odin (Fruits and Vegetables Subscription Service), and EcoLab (Cleaning Sanitation). Despite the importance of these examples they do not suggest a massive adoption of the concept of PSS; there are more projects from innovative firms or communal services. Another case presented by Ness [9] is HP solutions, a technology based business oriented to lease ICT hardware and software to other businesses on a monthly basis 
contract. This example is mainly supported by end-of-life strategies to collect, remanufacture and reuse their products [9]. Despite that this example shows some changes in the product design mainly focused on IT capabilities to provide services, it is developed by a large company and the model presented to develop PSS lacks enough detail to enable future replications. Finally, Van Halen et al. [29] present a complete methodology to develop PSS that claims to be applicable to different kinds of firms however the methodology requires well structured organizations able to build, for example, a dedicated team to develop the PSS or to have the resources to work with an external expert team. These requirements and the way the methodology is organized by phases, steps and processes is far too complex for SMEs with the characteristics and limitations identified in the SMEs considered during this study. Additionally, this methodology is not focused on the development of PSS based on the use of ICTs and the implications of these technologies for the design process and the resulting products.

Consequently, there is not widespread use or adoption of the PSS concept, and even less for sustainable PSS. There is also a lack of direction on how to develop these systems in SMEs and in developing economies specifically. It implies a lack of methodologies to decide if a sustainable PSS as a business model is suitable for a particular SME in a particular industry and later lack of guidance on to develop the systems taking into account the strengths and weaknesses of these kinds of firms. Despite the implications of a PSS for the design process, there is also a lack of formal methods to orient product design towards the development of sustainable PSS in SMEs. In the following sections some characteristics of product design that makes this process of particular importance for the development of sustainable PSS will be presented and later the potential contribution from ICTs to this development.

\subsection{Product design: a key factor for PSS}

Different authors have described the importance of the design process and its influence on the 
product life cycle and on the firm's performance. March-Chorda et al. [30] and Mascle and Zhao [31] present evidence that shows how a successful product design and development process in terms of time and innovation has a positive effect on the firm's competitiveness. Walsh et al. [32] present good product design as one of three ways to increase industrial competitiveness at the same level of product and process innovation. More arguments that support the positive relationship between design orientation and competitiveness, innovation and industrial performance especially in SMEs are presented by Moultrie et al. [33]. Finally, according to Mascle and Zhao [31] up to $80 \%$ of development, manufacturing and use costs associated with the product are originated in the design process. Esslinger [1] mentions in that sense the great opportunity that designers have to affect positively the resulting product in terms of sustainable performance.

However design practices are usually undervalued or even not considered on their own in SMEs [33]. This marginalization of design practices in SMEs can affect the development of PSS. First, because the idea to develop a PSS relies on innovative design and redesign of products and services demanding that companies are highly design oriented, and second because the lack of understanding of the design process makes it difficult to identify the possible contributions of product design to the development of sustainable PSS. The approach explored in this research looks to analyze the design process in SMEs considering ICTs as a transforming agent to produce changes into the design process and the resulting products that can contribute to develop sustainable PSS. Buyukozkan et al. [34] mention how ICTs transform the design process making it more oriented to information management than products. This idea is fundamental to connecting the use of ICTs with the development of sustainable PSS through the design process. Moreover Davenport and James [17] in an early work about the impacts of ICTs in organizational redesign processes highlighted how ICTs are a transforming force that directly impact on how a firm designs and develops their 
products. However, little has been done to understand the specific changes that ICTs can produce in the design process and in the resulting products of SMEs in the context of sustainable PSS development.

\subsection{Information and Communication Technologies}

The adoption and use of ICTs in industry presents opportunities to contribute to sustainable development. These opportunities include development of smart green products, servicing, and development of more efficient communication processes between stakeholders, virtualization, and dematerialization of offers, green purchasing and general industrial efficiencies [12], [13]. Regarding the contribution from ICTs to the development of PSS, previous work [3], [4], [6], [8], [11], [35] mention ICTs as mean to achieving practical examples and to establishing concrete measures and performance indicators but without clarifying the route to achieving these contributions. Also, Ness [9] presents a particular relationship between the use of ICTs and the development of sustainable PSS but focused only on virtualization and e-commerce platforms. Finally, dematerialization of offers through virtualization using ICTs in sustainable PSS is also mentioned by UNEP [36] presenting as examples online payment platforms, online services such as banking and digital music exchange, but even this does not explain how the connection between ICTs and the development of sustainable PSS could be developed and exploited.

It is now widely recognized that the use of technologies and development of e-business is im portant [37], and these technologies are changing current business models and consumption b ehaviours [38]. Also it mentioned is the necessity for almost every organization, despite their size and market, to consider the development of e-business units responding to the challenges and opportunities posed by new technologies [37].

Despite these facts, literature confirms the lack of evidence about the possible contribution of ICTs to the development of sustainable PSS. The examples found in the literature suggest a 
similar point of view mainly focused on virtualization and online services including ecommerce, but as discrete elements in the business models and not as a transforming agent in the organizations. ICT could have a much greater influence in the development of sustainable PSS for example through the changes that new technologies can produce in the design process [5]. This potential contribution is behind the objectives proposed in this research. For these reasons in the next section the gap in knowledge is presented that justifies the exploration of PSS, sustainability, ICT and design in relation to the development of sustainable PSS in SMEs.

\subsection{Gap in knowledge}

When considering developing sustainable PSS that take advantage of the changes that ICT can bring about in the design process and in the resulting products it is necessary to first understand how SMEs view the idea of developing PSS and what the relationships are between these elements in this context.

Previous studies have dealt with the relationships between some of the elements considered in this research or with one of the elements in the context of SMEs but there are no previous studies that considerer the integration of the three elements: ICTs, sustainable business development and the design process in SMEs in the context of sustainable PSS development. For example Moultrie et al. [33] present a detailed review of the importance of the design process in SMEs including an audit tool to assess design practices in these firms. Borja de Mozota [39] developed a design management model for European SMEs analyzing data collected from 33 SMEs during the European Design Prize 1997 using personal surveys. Related also to design in SMEs there is previous work on innovation and design thinking in SMEs [40], [41]. In terms of ICTs in SMEs Chapman et al. [42] dealt with building Internet capabilities in SMEs through a programme of assistance covering business analysis, IT and funding. The programme was assessed after the business analysis using a telephone survey. 
Taylor and Murphy [43] analyze the adoption of e-business practices in European SME and Monge-Gonzalez et al. [44] present a study of the impact of ICT on Central American SMEs' performance. Considering sustainable strategies in SMEs Moore and Manring [24] present an analysis of the potential benefits for SMEs of becoming more sustainable particularly related to the relationships with other stakeholders. Finally Cook et al. [45] build a framework to transfer the concept of PSS into UK manufacturing companies using semi-structured interviews and focus groups to identify the influent factors in the adoption of the PSS concept.

To fill this gap, the research presented in this paper is an exploratory study to make an initial diagnostic about the perception of SMEs of the concept of PSS. The results of this exploration are also the basis of a future reference model intended to lead the development of PSS in SMEs. A first version of this model is presented in the discussion as part of the future research in the field.

\section{METHODOLOGY AND COLLECTION OF DATA}

The methodology followed was exploratory qualitative research using a survey with 38 Colombian SMEs coming from different industries and backgrounds. This section outlines the data collection methods and the main features of the SMEs involved in the survey.

\subsection{Collection of Data}

Following the literature on qualitative methods in organizational research an exploratory qualitative approach was undertaken [46-48]. An online self-administered survey was used as the research method to develop the study [49]. This survey was developed from the literature and refined through a pilot study with a small group of SMEs before it was sent to the main group. The collection of data was carried out in cooperation with the Colombian Ministry of ICTs. This Ministry has been developing a programme of assistance to encourage the 
adoption and use of ICTs in SMEs over the last three years. The programme called "MiPYME Digital" jointly finances, with ICT’s suppliers, projects to implement ICTs in SMEs from diverse industrial sectors. This cooperation with the Colombian Government was possible to a great extent because of the economic, social and political situation that Colombian is in. According to Economist Intelligent Unit [50] Colombian is one of the CIVETS countries. This classification means that during the next few years a great transformation of the Colombian economy is expected, attracting foreign investment and developing the conditions to become a developed economy mainly supported by a stable political situation, young population and a dynamic economy. In order to orient that productive transformation towards sustainability policies have been developed recently. Within these policies are, for example, Law 216/2003 that "assigns the Ministry of the Environment, Housing and Territorial Development the function to adopt sustainable criteria in the management of the productive and institutional sectors, incorporating environmental management systems, technological reconversion and change of consumption habits between others to improve environment quality, make a rational use of the natural resources, protect the environment and improve the quality of life of the Colombian Society" and "CONPES 3484: The National Policy for the productive transformation and promotion of Micro, Small and Medium enterprises, an public-private effort" [51], [52]. In this sense it is in the Colombian Government interest to establish a mechanism of cooperation to achieve that productive transformation following sustainable principles. One of the objectives of the cooperation with the Colombian Ministry of ICTs to develop this research is to identify new paths to reorient “MiPYME Digital” project in the future.

In this context the survey was sent with a presentation of the research describing objectives and scope by email to 1600 SMEs involved in the first version of “MiPYME Digital 2008”. From the 1600 emails 300 failed to be delivered leaving 1300 usable emails. From them and 
after three months of follow-up 38 successfully completed questionnaires were returned. The initial response rate calculated directly from the 1300 emails is near 3\%, a very low rate even for an Internet survey [46]. However it was not possible to determine how many of the 1300 emails were in use. The majority of these email accounts were created during "MiPYME Digital” project in 2008 and there were no reviews to check that the SMEs were still using these accounts. For this reason the response rate does not give precise information about the attitude of the SMEs to this study but in general it leaves a question open about the means that should be used to involve this kind of firms in future stages of the research.

In the survey the SMEs were questioned about business strategy, use of ICTs, their design process and their perception of sustainability. Figure 1 shows a summary of the type of firms included in the study according to the International Standard Industrial Classification of all Economic Activities (United Nations).

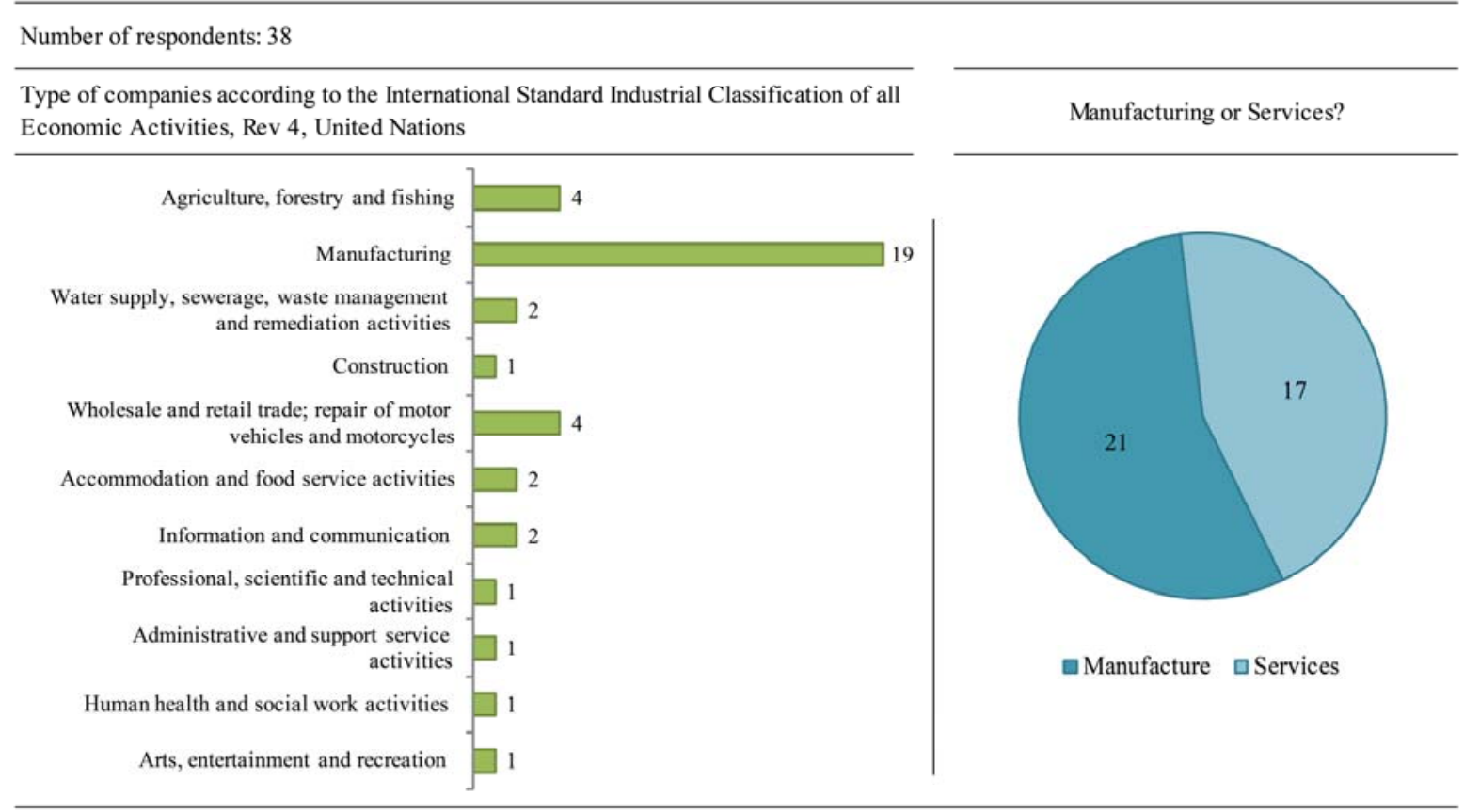

Figure 1: Type of companies considered and main industry focus

In terms of number of employees there were firms with just one employee to the largest with 
ninety-two. The group of companies participating were located in different areas of the country with one large group in Bogotá, the capital city of the country.

\subsection{Main features of the SMEs involved in the study}

The term "MiPYME" in Colombia makes reference to Micro, Small and Medium Enterprises and covers the general definition of SMEs [53]. In this sense Colombia is considered a SME country. According to the census done by DANE [54] in Colombia $99.86 \%$ of the total number of companies are SMEs. These SMEs are responsible for $80.8 \%$ of the total employment of the country and contribute 37\% to the national GDP (Gross Domestic Product), [54]. From the total number of SMEs 96.4\% are micro enterprises with one to ten employees.

Because of the importance of these kinds of firms for the Colombian Economy different studies have tried to identify the characteristics in them that create difficulties and barriers to their development [51]. The characteristics that have been identified are: high levels of informality, low levels of networking, in general they don't diversify, they have low technological levels and low human capital training, limited access to the financial sector, management of SMEs are too cautious to invest, SMEs don't have the competences to innovate and they have a very low use of ICTs. Between these features the low rate of ICT adoption has been a topic of discussion in the country, and one area chosen to develop programmes of assistance such as “MiPYME Digital”. The figures about adoption and use of ICTs in SMEs say that less that 20\% of Micro enterprises in Colombia use computers, the Internet and have a website [55]. For small firms the use of computers and the Internet increases but the presence on the web is still under 30\% [55]. For this reason and taking into account the hypothesis proposed, working with firms previously involved in "MiPYME Digital” project was of great value for the research. This kind of cooperation is aligned to the idea exposed by De Bruijn and Tukker [18] with governments and industry working together 
beyond legislation.

\section{MAIN FINDINGS}

\subsection{Perception of sustainable PSS in the SMEs}

A general definition of PSS similar to the one presented in section 2.1 with a short example, both taken from Manzini and Vezzoli [6], were given to the SMEs. With this preamble the firms were asked if they believe they had a PSS and the results showed that just few firms believed they offered a PSS, (Figure 2). However, they had a positive perception about the possibility of offering one. More than $60 \%$ of the SME involved thought that they could offer a PSS in their current conditions. It is interesting that any firm that affirmed to be able to develop a PSS recognizes the barriers identified in the literature to design and implement a PSS. When the firms were asked if they thought offering a PSS could bring advantages to their firms, 33 SMEs agreed, just one disagreed and four were unsure, (Figure 3).

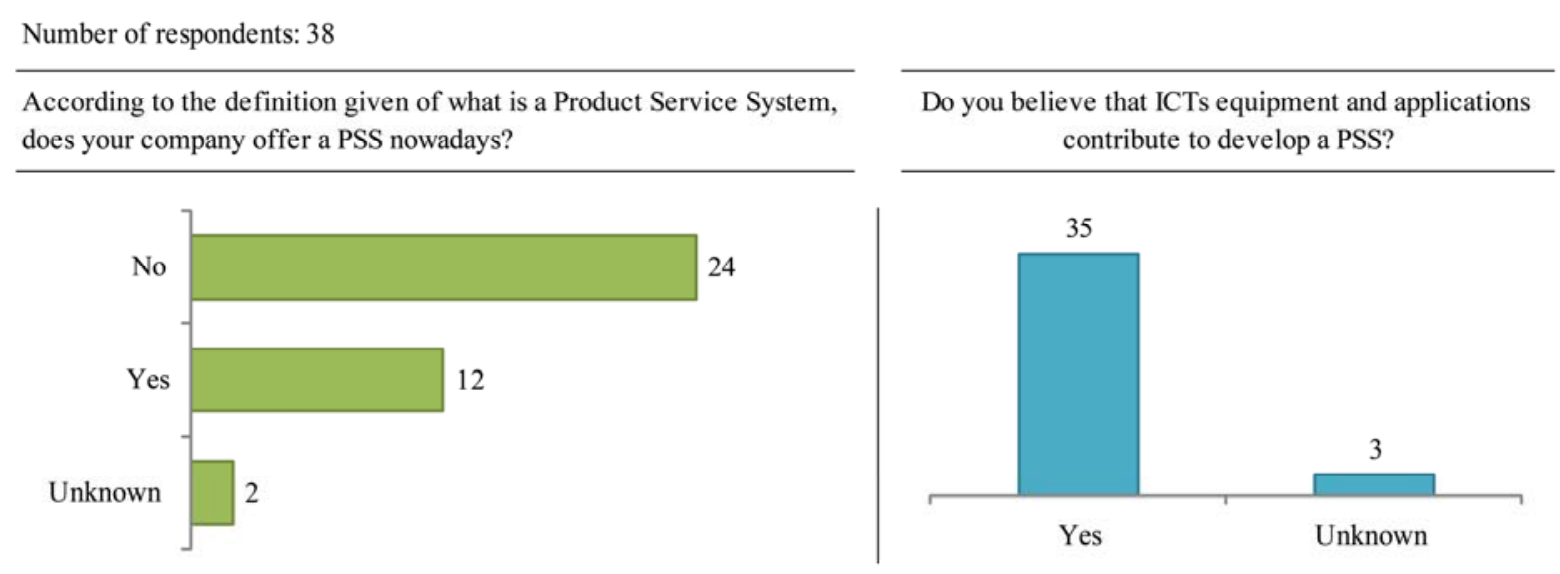

Figure 2: Current offer of PSS in the SMEs 


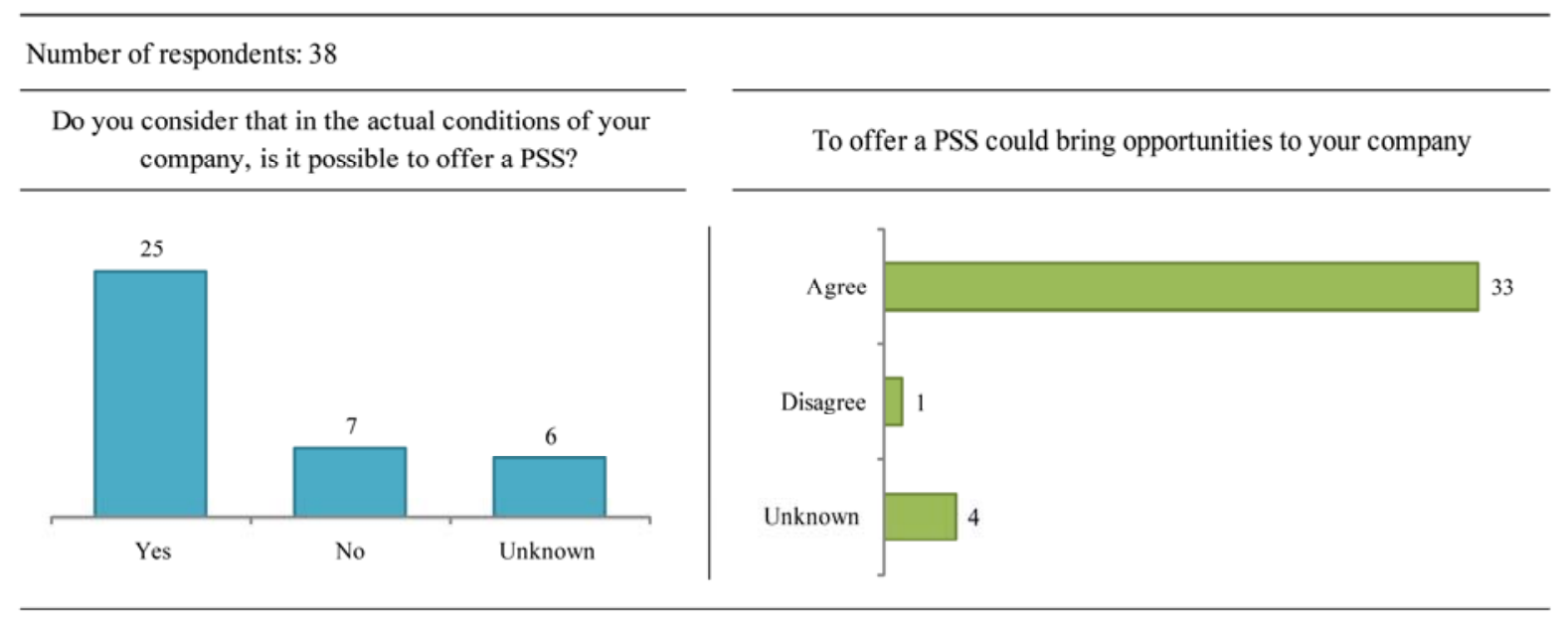

Figure 3: SME perceptions of PSS

The main advantage identified was the possibility to enrich their offers with associated services. They believed new services could help them to gain competitiveness, loyalty from customers and increased sales, aspects that are all part of PSS drivers and benefits identified in the literature. However companies did not mention other benefits such as enhanced innovation capacity, more flexibility and better environmental performance, just one SME showed an understanding of the advantages of a PSS as a means to achieving organizational change. Additionally, the firms apparently did not see the possible advantages of a PSS related to the relationships with other stakeholders except from the relationship with their customers. However, there was no mention of changing how they satisfy their customers. The comments on this subject were more oriented towards identifying their needs. Important advantages identified in the literature to achieve sustainable results through PSS are related to dematerialization, with intensification of product use in innovative schemes and efficiencies in the supply chain, but these were not mentioned by the SMEs. Some of the firms that agreed PSS could bring advantages to their companies but they also recognized that despite the advantages they do not have the knowledge to develop and implement a PSS:

My product is food, but I do not know if making and creating sub-products belongs to this kind of question that you are asking me, but I would like to know, if it does belong, how to 
do it,"Owner-Manager Food SME

Because this system is characterized by the satisfaction of the client in specific aspects, if my company was offering them it would increase the demand for a new service, but it is not clear to me how to implement this system in my textile company,"Manager Textile SME

Finally, the SMEs were asked about the potential environmental benefits of implementing PSS as a business model. In this sense the SMEs were more likely to associate the PSS environmental benefits with actions such as recovering and recycling products and materials. Other companies mentioned the idea that a PSS produces less emissions and pollution, but did not explained why or how they perceive this opportunity. It is notable that other environmental benefits of a PSS identified in the literature such as dematerialization, encouraging sustainable consumption and intensification of product use were not mentioned by the firms. It confirms a limited understanding of the PSS concept and areas suitable to be filled with a more complete presentation of the implications, benefits, main features and opportunities of a sustainable PSS. In this sense just one company exposed a systemic perspective of the relationship between industrial operations and environmental performance but oriented mainly to better control of process than to innovative ways to satisfy their customers:

Having a view over the whole productive process we can control and implement systems that benefit the environment. Example: GAP (Good Agricultural Practices)," Legal Representative Agriculture Association

\subsection{Awareness and understanding of sustainability in the SMEs}

Having a defined business strategy was identified in the literature as a very important driver for developing sustainable businesses, adopting and using ICTs and developing sustainable PSS. However, less than half of the firms surveyed stated that they had a business strategy and only three mentioned having a product, service or process certification (Figure 4). In 
terms of awareness of sustainability the firms were asked if they believed their operation was sustainable. It is interesting that half of the firms perceived their actual operation as sustainable despite previous studies where the lack of awareness and knowledge of environmental legislation and social responsibility have been mentioned as an important barrier to developing sustainable strategies in SMEs [21], [22]. According to the firms that did not consider that they had a sustainable operation the main reasons were lack of resources, tools and technical knowledge to participate in sustainable markets. This shows an understanding of sustainability as the opportunity to produce and sell sustainable products, which is a simplification of the implications of having a sustainable operation.

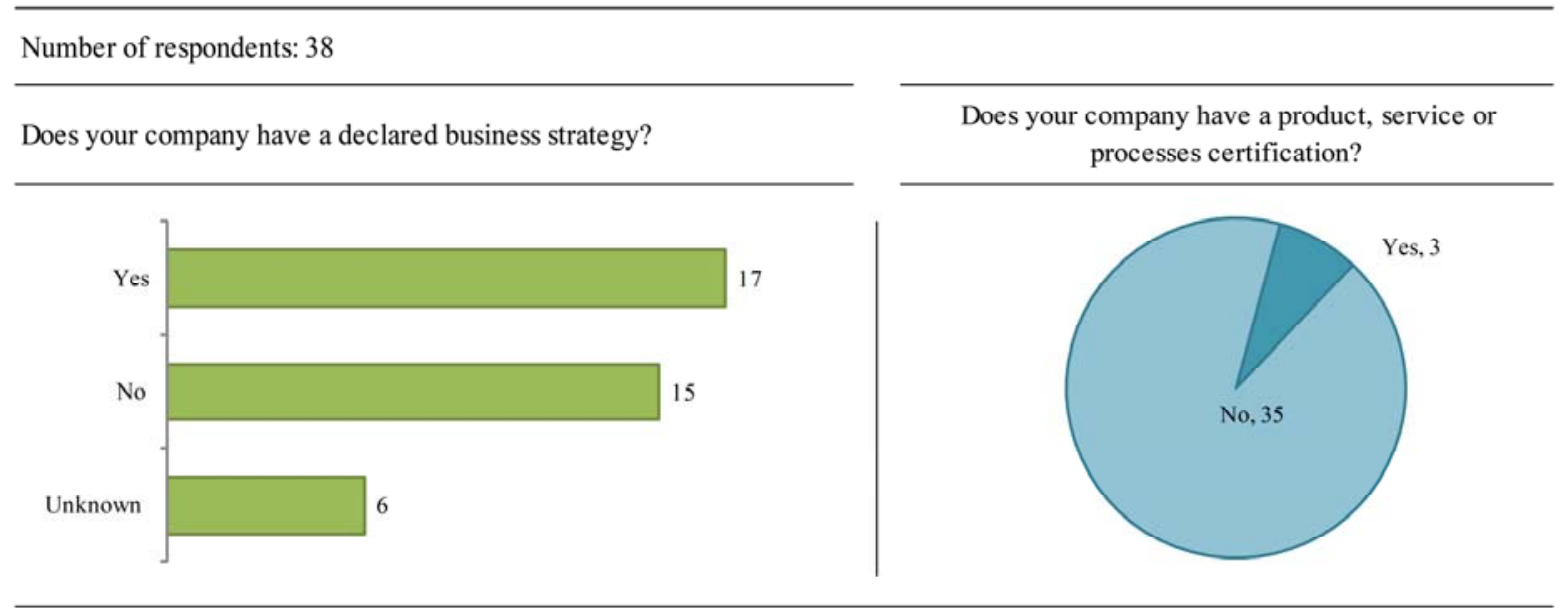

Figure 4: Business strategy and certifications

This kind of partial understanding of sustainability is also evident in the comments from the firms that affirm to have a sustainable operation and only explain it in terms of good environmental practices, (Figure 5). 


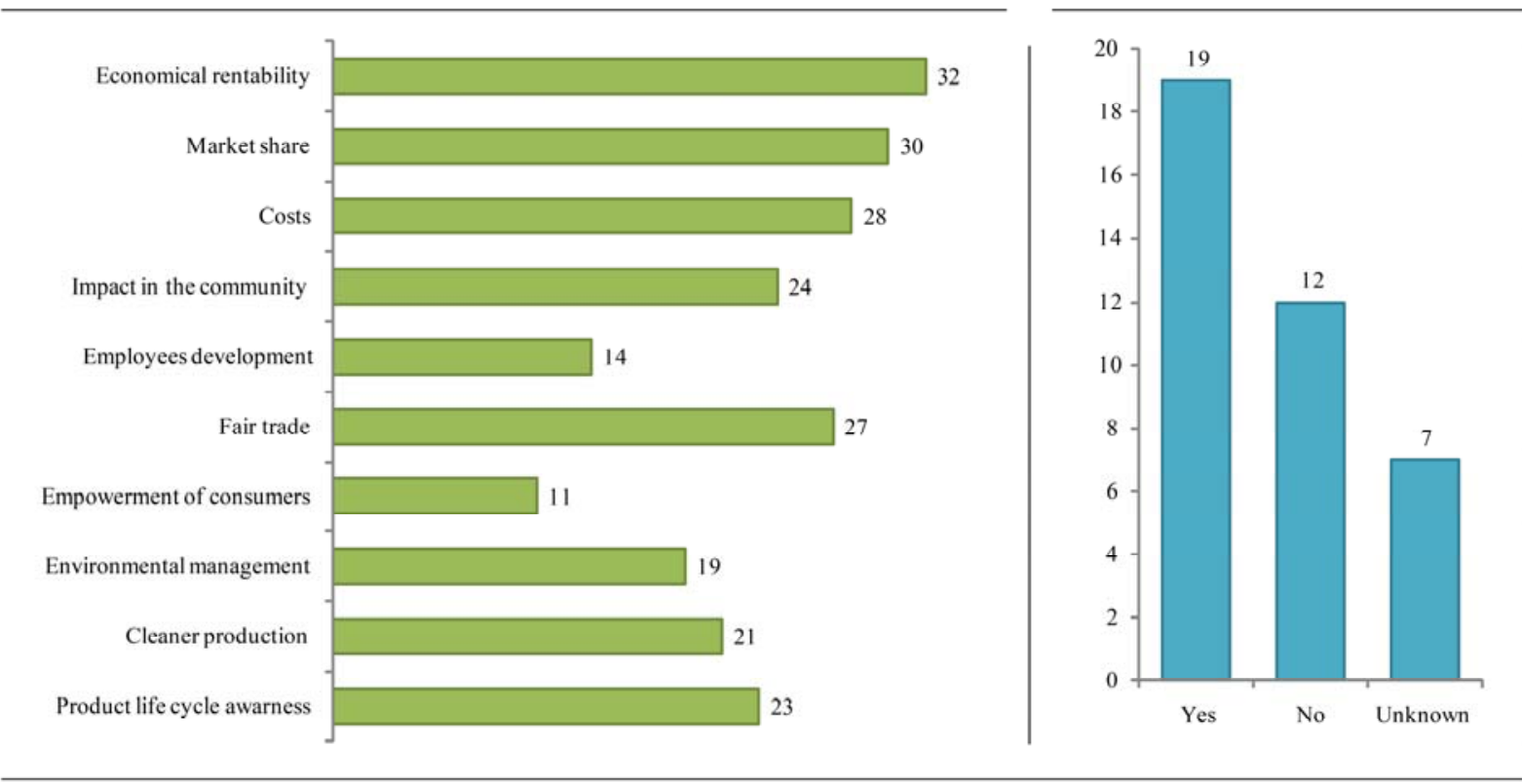

Figure 5: SME perceptions of sustainability

Initial positive feedback about the work of the firms on sustainability was the inclusion of fair trade, impacts on the community, cleaner production and responsibility over the whole product life cycle as part of their objectives and organizational policies for at least 20 firms. However these aspects are overshadowed by economic profitability, market share and costs as the three more frequently mentioned aspects,

\subsection{Use of ICTs in the SMEs}

In terms of ICTs, firms were interrogated on what were the most used technologies in their firms and what the main motivations were for adopting and using those technologies. In the first question the top five most used technologies were: e-mail, Internet, fixed line phone, computer and printer, (Figure 6). In this question very basic ICTs such as fixed line phones or printers were included, in order to establish the stage of adoption of technologies the firms were at. A complete list of ICTs presented by Kotelnikov [56] was included in this question as a frame of reference. According to his model of adoption and use of ICTs in SMEs, almost 
all the firms interrogated are in early stages of adoption with basic technologies for communication and for information management. Just a few firms use specialised software such as ERP, CRM or inventory management programs. Additionally only eight SMEs stated that they used e-commerce despite 24 claiming to have a website (Figure 6).

Finally, in order to assess the perception of the firms of the relationship between the use of ICTs and the development of PSS, the firms were asked about the potential contribution of these technologies to develop a PSS in their firms. In this case 35 SMEs said ICTs can contribute and just three firms were unsure about it. This initial perception is a key reason that the research is exploring the possible contribution of ICTs to the development of sustainable PSS. If the firms believe in the potential of ICTs to build these kinds of systems it may be possible to introduce the idea of integration and move the firms towards sustainability.

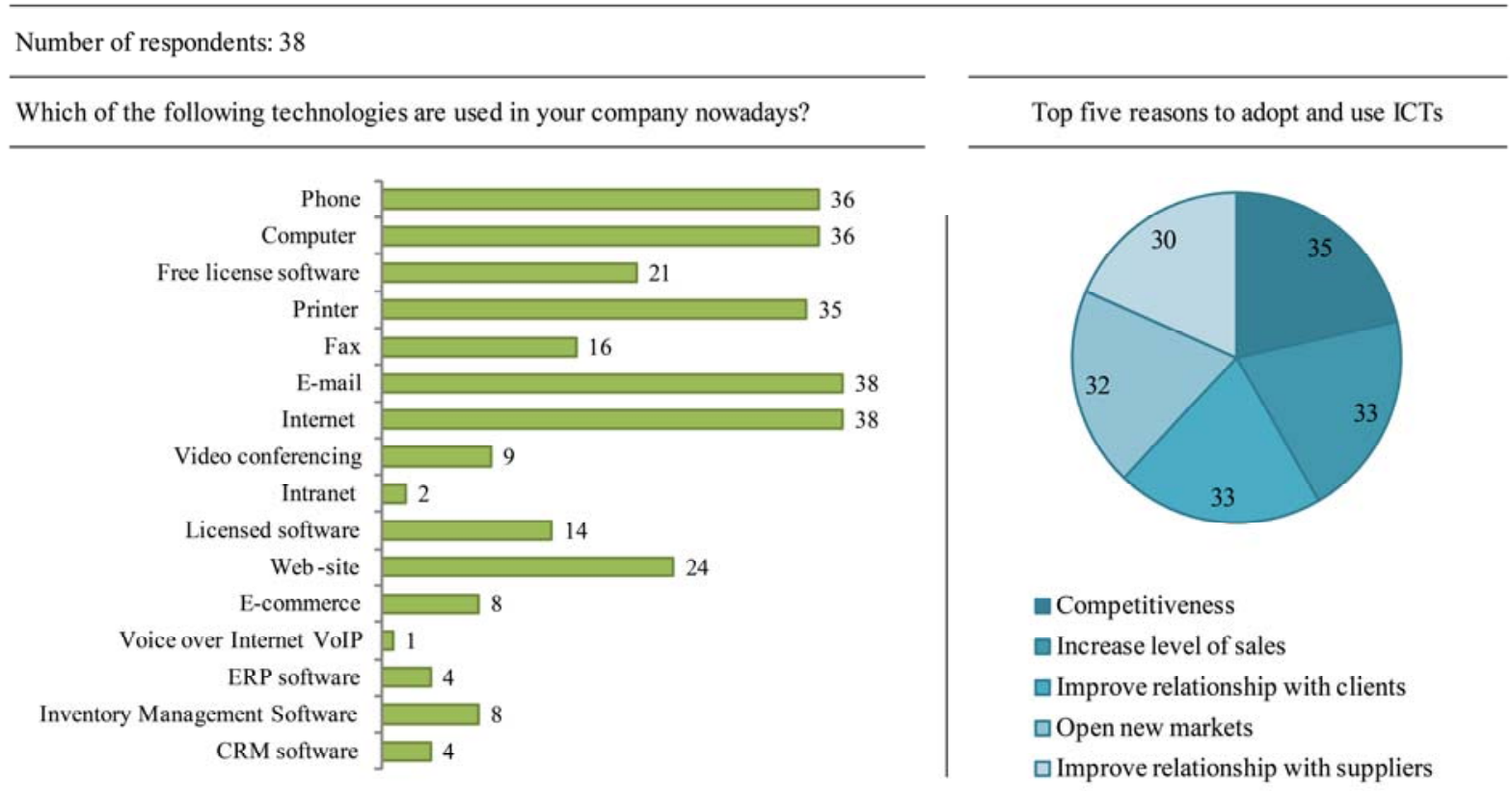

Figure 6: Technologies used in the SMEs and top reasons to use them

The positive perception of the firms to use ICTs and that this use can contribute to develop PSS was mainly related to three potential aspects. First, ICTs can facilitate and improve 
communication with clients. Second, ICTs can be the means to offer additional services associated with the products that they already provide and third ICTs can bring the opportunity to be more efficient and assertive in their operating and administrative processes. The first two contributions mentioned above are the most common connections between ICTs and PSS proposed in the literature with the inclusion also of improved communication with other stakeholders, but this point is continually missed in the comments from the SMEs, they showed a clear focus on their relationship with customers ignoring other stakeholders.

The last potential contribution mentioned for some firms, despite it not being fully explained, is a surprising result. The connection being explored to develop sustainable PSS supported by the potential changes in the design process, and in the resulting products from the use of ICTs, fits with the opportunity to be more efficient and assertive as a company. However this opportunity and the development of sustainable PSS demand a radical change that goes further than process efficiency. Finally, we can conclude that there is an interesting opportunity to keep exploring the path proposed. However, and despite the positive perception of the topics, it is possible to see that the firms do not fully understand the concept of PSS, its barriers, benefits and requirements. The possibility to develop a sustainable PSS has to be supported by more than a positive perception.

\subsection{Analysis of the SMEs with a Design Process}

Taking into account the integration proposed between ICTs and sustainable PSS exploring the design process as a path in this integration, the research was particularly interested in the group of SMEs that stated they had a design process in-house. Instead of giving the firms a definition of an in-house design process, the firms were asked a multiple choice question enabling firms to say if they had a design process or not. From the 38 SMEs considered initially, 20 stated that they had a design process in-house, (Figure 7). 


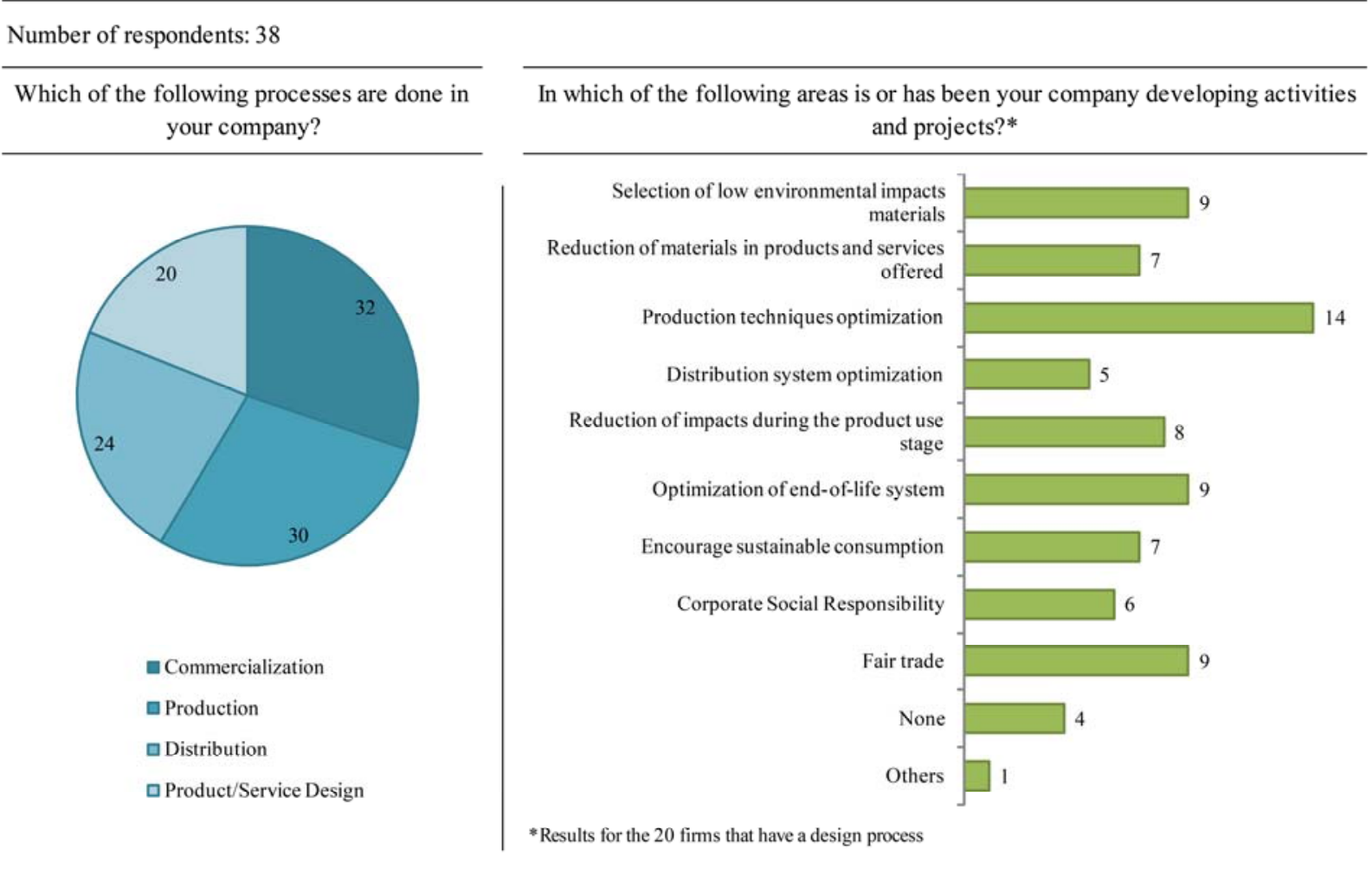

Figure 7: Firms with design process

In this subgroup 15 SMEs were manufacturing firms and five service firms. With this proportion the first result was that from the 20 firms five SMEs stated, according to the definition of PSS, that they already had one, these were all manufacturing companies. None of the five firms classified as being in the service industry believe they have a PSS even when they could be considered closer to the principles of a PSS. However four of these five service firms believe that in their current conditions they could offer a PSS, while from the 15 manufacturing firms not already offering a PSS just four think they can offer a PSS in their current conditions.

This last result taking into account the proportion of firms in each industry (manufacture and service) shows a higher potential opportunity to develop a PSS in service firms. Despite that, 13 of the manufacturing firms who have a design process in-house believed a PSS could bring advantages to their firms. It is also interesting that from this group of 20 SMEs that have a design process, eight firms have a declared business strategy and from them seven 
were manufacturing firms and only one a service SME. Traditionally, Colombian manufacturing industry has been more structured than the service industry. This could have influenced how well defined the SMEs are. The top five areas related to sustainable business development in which these 20 SMEs have been developing projects were: production techniques optimization, optimization of the product end of life system, selection of low environmental impact materials, fair trade and reduction of impacts during the product use stage. It is very promising that in these areas particular applications of ICTs to contribute to sustainable business development have been identified. For example, optimization of production techniques relates to industrial efficiencies and dematerialization, optimization of end of life systems to design of smart green products and customer empowerment and fair trade to social inclusiveness. These connections have strong relationships and implications to almost every process in a SME but with special emphasis on the design process.

\section{DISCUSSION}

The SMEs considered in the study show a positive perception about adopting new and more innovative business ideas such as PSS to satisfy their customers. It is interesting to note that less than a third of the firms mentioned e-commerce, even if it is a common ICT application, and one that has major potential in aiding the development of PSS, as recognized in the literature. This finding has strong resonance with a UK-based study into SMEs understanding and adoption of new business concepts that found that they were more likely to concentrate on short term gains rather than consciously developing new business competencies [57].

Considering the low proportion of firms that already offer a PSS it is an important result that more than $60 \%$ of them believe they can offer one and moreover that 33 SMEs consider a sustainable PSS could bring advantages to their firms. It shows a positive perception and attitude facing the idea to make radical organizational changes. This disposition to change was identified in the literature as one relevant requirement to design and develop sustainable 
PSS [8], [58]. However it was also possible to see in the results that there is only a partial understanding of what a sustainable PSS is and what their requirements are. Not only were some benefits not mentioned but also the possible barriers to deploy these kinds of business schemes were ignored. The only possible barrier mentioned was the lack of knowledge but others such as public acceptance, financial uncertainty or difficult relationships between stakeholders, all identified in the literature [8], [58], were not mentioned.

In terms of the contribution of ICTs to sustainable PSS, the connection proposed through the design process and the resulting products was not clearly identified in the results as one of the potential contributions according to the SMEs. However, some of the firms considered that using ICTs makes their processes more efficient and they believe these advantages contribute to designing and developing PSS. This reasoning can facilitate the development of PSS but it is necessary to clarify the nature of the changes caused by the use of ICTs in the design process and in the resulting products in SMEs and work with the changes that can be permanent practices towards sustainable PSS. Despite only half of the firms having a declared business strategy there is awareness of the importance to behave in sustainable ways as represented in aspects such as fair trade, impacts on the community and product life cycle awareness included in their organizational planning. However, economic interests such as economic profitability, market share and costs exceed these aspects. Furthermore according to the results there is no knowledge of the whole set of benefits a sustainable PSS can bring especially in environmental terms. These benefits were reduced mainly to recycling systems. With regards to the 20 firms that said they had a design process, it was observed that manufacturing firms are less confident of the possibility of offering a PSS than service firms. This result confirms that the integration proposed through the design process could be a very useful way to introduce these manufacturing companies to sustainable business practices particularly sustainable PSS. In these 20 firms a lack of a declared business strategy was also 
evident. It is an aspect that can make the deployment of sustainable PSS difficult. Taking into account the top five areas related to sustainable business where these 20 firms have been developing projects, there was no evidence of connections between these areas and particular ICT applications that could favour the development of sustainable PSS. In the end there is a great opportunity and range of action to work with the positive perception of these firms, however there is a necessity to understand better their design process and how the use of ICTs affect that process and the resulting product. This understanding is the base to identify the changes that could contribute to develop sustainable PSS.

Connecting the results of the literature review and the findings of the survey and its analysis, a preliminary version of a reference model was developed (Figure 8). This reference model is the basis of a possible future route to orient the development of PSS in SMEs. 


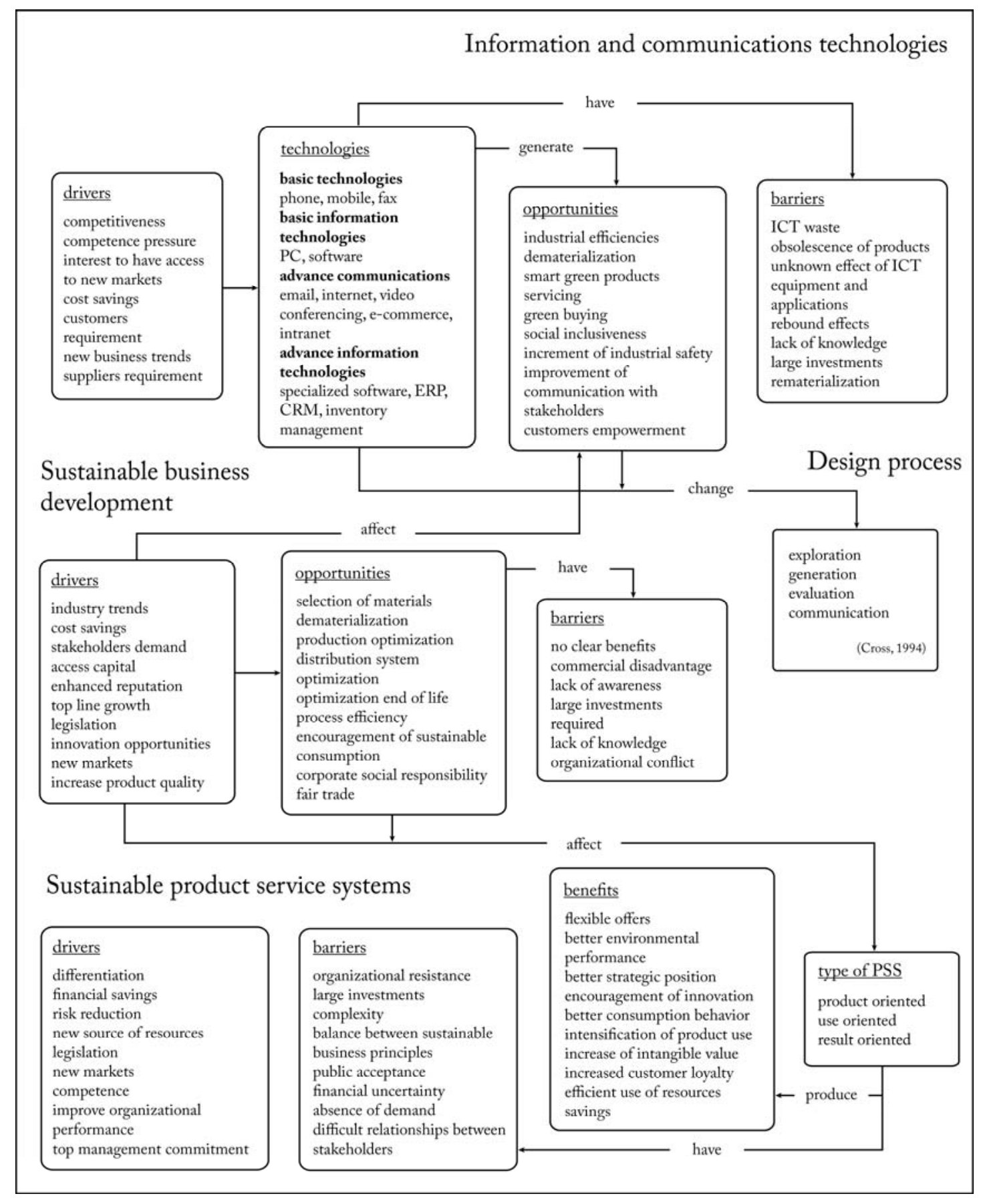

Figure 8: Preliminary version of a reference model to orient the development of sustainable PSS

Included in this preliminary version of a reference model are the aspects that may have an influence on the development of sustainable PSS in the three areas explored in the research: ICT, sustainability and design. In each area drivers, barriers, opportunities and benefits of 
these areas were identified in relation to sustainable PSS development. Additionally a set of preliminary relationships between these elements is presented in the model. The purpose of this model is to be the basis of future deeper exploration of these areas that helps to exploit the opportunities and overcome the potential barriers and difficulties in the development of sustainable PSS.

\section{CONCLUSION}

In terms of the objectives proposed for this research the main conclusions are:

- For the SMEs involved in the study aspects related to sustainable business practices are not the main focus in their objectives and organizational planning confirming previous literature, however they have been developing projects related to these aspects. These applications should be used as a starting point for a transformation towards sustainable PSS.

- There is a general lack of understanding in the SMEs about what sustainability means and what the implications are for them to transform their operations towards sustainability. This lack of understanding could be a serious obstacle to execute an organizational intervention toward sustainable PSS development.

- The main reasons in the SMEs to adopt and use ICTs are related to economic indicators and there is no evidence of connection between that use of technology and the development of sustainable PSS, even when the majority perceive that connection as positive.

- The lack of formal business strategies in manufacturing firms with a design process suggests that further work is needed on this area before thinking about developing sustainable PSS involving these firms.

On the basis of the presented study and relevant literature it is clear that the positive perception of these SMEs to face organizational changes and to use ICTs has to be better 
oriented towards sustainable business practices, and further research with these firms could make that reorientation. However it is also very important to find mechanisms to determine on an individual basis when sustainable PSS and the integration of ICTs and the design process are suitable concepts for SMEs. It is also interesting to analyze further the low rate of response from the SMEs to the study that reached just 3\% respect to the whole set of firms approached. Despite that this rate could be higher taking into account only the emails in use at the moment of the study, it is possible that the SMEs whose responded the survey are the ones more motivated to keep contact to the project "MiPYME Digital" and in that sense the rest of the firms involved in "MiPYME Digital" project could not share completely their vision and perception on PSS and use of technologies.

\section{REFERENCES}

[1] H. Esslinger, "Sustainable Design: Beyond the Innovation-Driven Business Model," Journal of Product Innovation Management, vol. 28, pp. 401-404, 2011.

[2] P. Hofman and T. De Bruijn, "Facilitating sustainable innovation through collaboration: a multi-stakeholder perspective,” Springer, 2010, pp. 115-134.

[3] R. Roy, “Sustainable product-service systems,” Futures, vol. 32, pp. 289-299, 2000.

[4] A. Tukker, "Eight types of product-service system: eight ways to sustainability? Experiences from SusProNet," Business Strategy and the Environment, vol. 13, pp. 246-260, 2004.

[5] R. J. Hernandez, T. Bhamra, and R. Bhamra, "Sustainable Product Service Systems in Small and Medium Enterprises (SMEs): Opportunities in the Leather Manufacturing Industry,” Sustainability, vol. 4, no. 2, pp. 175-192, Jan. 2012.

[6] E. Manzini and C. Vezzoli, “A strategic design approach to develop sustainable product service systems: examples taken from the 'environmentally friendly innovation’ Italian prize,” Journal of Cleaner Production, vol. 11, no. 8, pp. 851-857, Dec. 2003.

[7] M. E. H. Creusen, "Research Opportunities Related to Consumer Response to Product Design,” Journal of Product Innovation Management, vol. 28, pp. 405-408, 2011. 
[8] O. Mont, "Drivers and barriers for shifting towards more service-oriented businesses: Analysis of the PSS field and contributions from Sweden," The journal of Sustainable Product Design, vol. 2, pp. 89-103, 2002.

[9] D. Ness, "Sustainable Product Service Systems: Potential to deliver business and social benefits with less resource use," in Greening the Business and Making Environment a Business Opportunity. Bangkok, Thailand. 5-7 June., 2007.

[10] O. Mont, "Clarifying the concept of product-service system," Journal of Cleaner Production, vol. 10, no. 3, pp. 237-245, Jun. 2002.

[11] L. Erdmann, L. Hilty, J. Goodman, and P. Arnfalk, "The Future Impact of ICTs on Environmental Sustainability Technical Report EUR 21384,” 2004.

[12] C. Ryan, Digital Eco-Sense: Sustainability and ICT - A New Terrain for Innovation. Lab3000, 2004.

[13] N. Cohen, "E-commerce and enviroment," in Sustainability at the speed of light: Opportunities and challenges for tomorrow's society, Dennis, Ed. WWF Sweden, 2002, p. 64 to 75.

[14] D. Pamlin, “A report about ICT and Sustainability,” in Sustainability at the speed of light: Opportunities and challenges for tomorrow's society, D. Pamlin, Ed. WWF Sweden, 2002, pp. 6-11.

[15] GeSI Global e-Sustainability Initiative, "ICT Sustainability through Innovation. GeSI Activity Report,” 2009.

[16] T. Langrock, H. Ott, and T. Dworak, "Environmental friendly ICT-Products," in Sustainability at the speed of light: Opportunities and challenges for tomorrow's society, D. Pamlin, Ed. WWF Sweden, 2002, pp. 96-109.

[17] T. Davenport and S. James, The new industrial engineering: information technology and business process redesign. 1990.

[18] T. De Bruijn and A. Tukker, "Partnership and Leadership: building alliances for a sustainable future,” Springer, 2002, pp. 5-20.

[19] D. L. Rainey, Sustainable Business Development: Inventing the Future Through Strategy, Innovation, and Leadership. New York: Cambridge University Press, 2006.

[20] PricewaterhouseCoopers, “Sustainability Survey Report,” 2002.

[21] C. Van Hemel and J. Cramer, "Barriers and Stimuli for Ecodesign in SMEs," Journal of Cleaner Production, vol. 10, no. 5, pp. 439-453, 2002.

[22] F. Ciliberti, P. Pontrandolfo, and B. Scozzi, "Investigating corporate social responsibility in supply chains: a SME perspective," Journal of Cleaner Production, vol. 16, pp. 1579-1588, 2008. 
[23] J. Sarkis, J. Cordeiro, and D. Vasquez, "Facilitating sustainable innovation through collaboration: a multi-stakeholder perspective.,” Springer, 2010, pp. 1-16.

[24] S. Moore and S. Manring, "Strategy development in small and medium sized enterprises for sustainability and increased value creation," Journal of Cleaner Production, vol. 17, pp. 276-282, 2009.

[25] EUCommission, “Small, Clean and Competitive.” 2008.

[26] N. Llano, "Politica para la promocion en el acceso y uso de TIC en Micro, Pequeñas y Medianas Empresas Colombianas,” 2009.

[27] UNEP, “Towards a Green Economy: Pathways to Sustainable Development and Poverty Eradication,” 2011.

[28] I. Omann, "A multicriteria tool for evaluating the impacts of product service systems on sustainable development: An application in Austrian companies," SERI working papers, vol. 5, 2007.

[29] C. Van Halen, C. Vezzoli, and R. Wimmer, Methodology for Product Service Systems Innovation. Koninklijke Van Gorcum, 2005.

[30] I. March-Chorda, A. Gunasekaran, and B. Lloria-Aramburo, "Product development process in Spanish SMEs: an empirical research,” Technovation, vol. 22, pp. 301-312, 2002.

[31] C. Mascle and H. P. Zhao, "Integrating environmental consciousness in product/process development based on life cycle thinking," International Journal of Production Economics, vol. 112, pp. 5-17, 2008.

[32] V. Walsh, R. Roy, M. Bruce, and S. Potter, Winning by design: technology, product design and international competitiveness. Blackwell Publishers Cambridge Massachusetts, USA, 1992.

[33] J. Moultrie, J. Clarkson, and D. Probert, "Development of a Design Audit Tool for SMEs,” Journal of Product Innovation Management, vol. 24, pp. 335-368, 2007.

[34] G. Buyukozkan, A. Baykasoglu, and T. Dereli, "Integration of Internet and web-based tools in new product development," Production Planning and Control, vol. 18, pp. 4453, 2007.

[35] O. Mont, "Product-Service Systems: reviewing achievements and refining the research agenda,” Journal of Cleaner Production, vol. 14, pp. 1451-1454, 2006.

[36] UNEP, “Design for Sustainabilty D4S: A step by step approach,” 2009.

[37] D. D. Gregorio, S. K. Kassicieh, and R. De Gouvea Neto, "Drivers of E-business activity in developed and emerging markets," IEEE Transactions on Engineering Management, vol. 52, no. 2, pp. 155-166, May 2005. 
[38] S. Albers and M. Clement, "Analyzing the Success Drivers of e-Business Companies,” IEEE Transactions on Engineering Management, vol. 54, no. 2, pp. 301-314, May 2007.

[39] B. Borja de Mozota, "Design and competitive edge: A model for design management excellence in European SMEs,” Design Management Journal - Academic Review, vol. 2, pp. 88-103, 2003.

[40] A. Ward, E. Runcie, and L. Morris, "Embedding innovation: design thinking for small enterprises.,” Journal of Business Strategy, vol. 30, pp. 78-84, 2009.

[41] F. Jorgensen and J. Ulhoi, "Enhancing innovation capacity in SMEs through early network relationship.,” Creativity and Innovation Management, vol. 19, pp. 397-404, 2010.

[42] P. Chapman, M. James-Moore, M. Szczygiel, and D. Thompson, "Building Internet capabilities in SMEs,” Logistics Information Management, vol. 13, pp. 353-360, 2000.

[43] M. Taylor and A. Murphy, "SMEs and e-business.," Journal of Small Business and Enterprise Development, vol. 11, pp. 280-289, 2004.

[44] R. Monge-Gonzalez, C. Alfaro-Azofeifa, and J. Alfaro-Chamberlain, TICs en las PYMES de Centroamerica. Editorial Tecnologica de Costa Rica, 2005.

[45] M. B. Cook, T. A. Bhamra, and M. Lemon, "The transfer and application of Product Service Systems: from academia to UK manufacturing firms," Journal of Cleaner Production, vol. 14, no. 17, pp. 1455-1465, Jan. 2006.

[46] C. Robson, Real World Research. Blackwell Publishing, 2002.

[47] J. W. Creswell, Qualitative inquiry \& Research Design: Chosing among five approaches. SAGE Publications, 2007.

[48] C. Cassell and G. Symon, Essential Guide to Qualitative Methods in Organizational Research. 2004.

[49] R. K. Yin, Case study research: Design and Methods. SAGE Publications, 2009.

[50] Economist Intelligence Unit, "Beyond the BRICs,” Global Forecasting Service, 2010. [Online]. Available: http://gfs.eiu.com/Article.aspx?articleType=wif\&articleId=242. [Accessed: 15-Jul-2011].

[51] CONPES3484, "Politica Nacional para la Transformacion Productiva y la Promocion de las Micro, Pequeñas y Medianas Empresas: Un Esfuerzo Publico-Privado. Departamento Nacional de Planeacion, Colombia.,” 2007.

[52] UPME, “Agenda ambiental para los sectores del programa de transformacion productiva. Colombian Ministry of Environment, Housing and Territorial Development,” 2010. 
[53] EUCommission, “The new SME definition: User guide and model declaration.” 2005.

[54] DANE, “Departamento Nacional de Planeacion, Colombia. Censo General,” 2005.

[55] DANE, "Indicadores Basicos de Tecnologias de Informacion y Comunicaciones TIC. Modulos de Gran Encuesta Integrada de Hogares, Encuesta Anual de Comercio, Encuesta Anual Manufacturera, Encuesta Anual de Servicios y Microestablecimientos,” 2008.

[56] V. Kotelnikov, “Small and Medium Enterprises and ICT,” 2007.

[57] R. Bhamra, S. Dani, and T. Bhamra, "Competence understanding and use in SMEs: a UK manufacturing perspective,” International Journal of Production Research, vol. 49, no. 10, pp. 2729-2743, May 2011.

[58] A. Tukker and U. Tischner, "New business for old Europe: Product-Service Development as a means to enhance competitiveness and eco-efficiency,” 2004.

\section{APPENDIX}

Law 905/2004 of Colombian Government defines enterprises according to the number of employees and actives. Micro 1 to 10 employees and between 0 and 500 minimum salaries, Small 11 to 50 employees and between 500 and 5.000 minimum salaries, Medium 51 to 200 employees and between 5.000 and 30.000 minimum salaries and Large 201 or more employees and more than 30.000 minimum salaries. Minimum salary in Colombia 2011: \$535.600 Colombian Pesos equivalent approximately to $£ 184$.

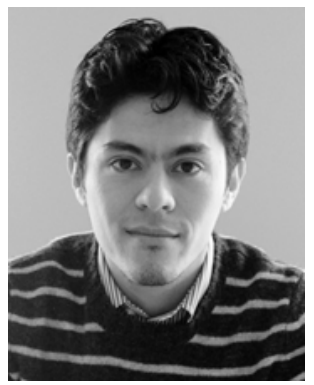

\section{Ricardo J. Hernandez}

Ricardo J. Hernandez holds a B.Sc. in Industrial Engineering from the Colombian School of Engineering, a M.Sc. in Industrial Engineering from the University of the Andes, Colo mbia and a Master Management Research with focus on Product and Service Design fro $\mathrm{m}$ the National Institute Polytechnic of Grenoble, France. Currently Ricardo is working t owards a Doctoral Degree at Loughborough University. Ricardo is undertaking a researc $\mathrm{h}$ in Sustainable Product Service Systems (PSS) supported by Product Design and Information and Communicat 
ions Technologies (ICT). Currently, He is Visiting Lecturer on Design for Sustainability in the Postgraduate prog rammes of the Business School at the University of the Andes in Colombia. Previously he has been Lecturer in $t$ he Industrial Engineering Department at the same University. His research has appeared in International Journal of Sustainable Engineering, Sustainability and Design for Innovative Value Towards a Sustainable Society. His r esearch interests comprise product and service design, sustainability in the design process, product service syste ms and ICT.

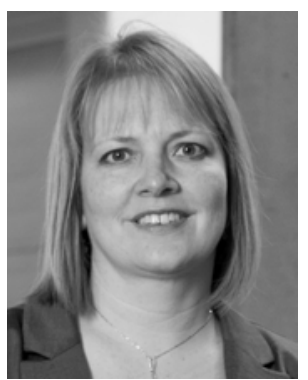

\section{Professor Tracy Bhamra}

Professor Tracy Bhamra has a BSc in Manufacturing and an MSc in Manufacturing Syste ms Engineering and Management. She then went on to complete her $\mathrm{PhD}$ in Design for Disassembly and Recycling at Manchester Metropolitan University. Professor Bhamra h as extensive research experience in the field of sustainable design initially during her $\mathrm{Ph}$ D and then following that at Manchester Business School and Cranfield University befor e joining Loughborough University in 2003. During this time she has been very active in developing the researc h area of Sustainable Design. Tracy has been involved in teaching since 1992 and teaches Sustainable Design on both undergraduate and postgraduate Design Programmes. Her research has been published in Journal of Cleane r Production, International Journal of Sustainable Engineering and Sustainability. Her book Design for Sustain ability: A Practical Approach was published by Gower in 2007. Her research interest include methods and tools $\mathrm{f}$ or sustainable design, sustainable product service systems and sustainable design strateg

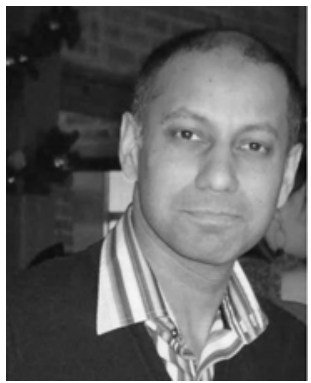
y.

\section{Dr. Ran Bhamra}

Dr. Ran Bhamra has a B.Sc. in Applied Physics from Kingston Polytechnic, a M.Sc. in Manufacturing Systems and Management from Bradford University and a Ph.D. from C ranfield University. Dr Bhamra is a Lecturer in Engineering Management at Loughborou gh University and also currently a Visiting Assistant Professor at Hong Kong University. Prior to this, his career was spent in a variety of engineering organisations, in engineering, process improvement and management roles. He teaches operations management and strategy on undergraduate and postgraduate engi neering programmes. His research has appeared in International Journal of Production Research, International Journal of Sustainable Engineering and Sustainability. His research interests include competence and resource-b ased theory, organisational resilience and sustainability in manufacturing strategy. 
